\title{
Impact of prosthesis-patient mismatch on short-term outcomes after aortic valve replacement: a retrospective analysis in East China
}

Lei Guo ${ }^{1+}$, Junnan Zheng ${ }^{1+}$, Liangwei Chen ${ }^{1+}$, Renyuan $\mathrm{Li}^{1}$, Liang $\mathrm{Ma}^{1}$, Yiming $\mathrm{Ni}^{1}$ and Haige Zhao ${ }^{1,2^{*}}$

\begin{abstract}
Background: Prosthesis-patient mismatch (PPM) may affect the clinical outcomes of patients undergoing aortic valve replacement (AVR). We aimed to determine the incidence of PPM, its effect on short-term mortality, and the factors contributing to PPM in China.

Methods: We retrospectively examined all consecutive patients with isolated or concomitant AVR at our hospital between January 1, 2013 and December 31, 2015. PPM was defined as an effective orifice area index (EOAi) of $\leq 0$. $85 \mathrm{~cm}^{2} / \mathrm{m}^{2}$. The baseline, echocardiographic, operative, and outcome data of all patients were collected from the national database.

Results: A total of 869 patients were included in the study. PPM was detected in 15.9\% (138/869) of the patients. Four patients $(0.5 \%)$ met the criteria for severe PPM. Patients with PPM were older and had a higher prevalence of diabetes, coronary heart disease, aortic stenosis (AS), and preoperative left ventricular dysfunction but a lower incidence of smoking history and aortic regurgitation. Logistic regression analysis showed that female gender $(P<0.001)$, AS $(P=0.014)$, higher body mass index $(\mathrm{BMI})(P<0.001)$, and bioprosthesis $(P<0.001)$ were independent predictors of PPM. We also found that PPM $(P=0.005)$ was associated with 30-day all-cause mortality, along with smoking history $(P=0.001)$ and low preoperative left ventricular ejection fraction (LVEF) $(P=0.004)$.
\end{abstract}

Conclusions: PPM is associated with high short-term mortality after AVR in China. Female gender, aortic stenosis, bioprosthesis, and high BMI are risk factors for the incidence of PPM.

Keywords: Prosthesis-patient mismatch (PPM), Aortic valve replacement (AVR), Aortic stenosis (AS), Effective orifice area $(\mathrm{EOA})$

\section{Background}

Prosthesis-patient mismatch (PPM) after aortic valve replacement (AVR) surgery was first mentioned in 1978 by Rahimtoola, and has been a topic of discussion ever since [1]. PPM occurs when the effective orifice area (EOA) of the implanted prosthesis is too small in relation to the patient's body size.

\footnotetext{
*Correspondence: 13732251173@126.com

${ }^{\dagger}$ Equal contributors

${ }^{1}$ Department of Thoracic and Cardiovascular Surgery, First Affiliated Hospital of Zhejiang University, School of Medicine, Hangzhou, China

${ }^{2}$ Department of Cardiothoracic Surgery, the First Affiliated Hospital, Zhejiang

University, 79 Qingchun Road, Hangzhou 310003, China
}

The clinical significance of PPM after AVR remains controversial even after 37 years since its first description. Some studies have showed favorable results despite the occurrence of PPM after AVR [2-4], while several other clinical studies have demonstrated that aortic PPM might be associated with an increased incidence of long- and short-term adverse outcomes, including cardiac-related death $[5,6]$. Patients with valvular diseases in East China have smaller body surface area, more rheumatic causes and lower anticoagulation intensity requirements [7]. Therefore the incidence, predictions and complications of PPM in East China patients might differ greatly from patients in the western countries. 
However, study regarding PPM in this specific group of patients has seldom been reported.

For these reasons, we retrospectively analyzed PPM in patients undergoing first time isolated or concomitant AVR in East China and aimed to determine the incidence of PPM, its effect on short-term mortality, and the factors contributing to PPM.

\section{Methods}

\section{Patient population and data collection}

This study was conducted at a single large cardiothoracic surgical center in southeast China. After obtaining written informed consent waived by the Hospital Review Board, we reviewed data from the Chinese Adult Cardiovascular Surgery Database, which holds clinical information on all patients at the center, the Department of Cardiothoracic Surgery at the First Affiliated Hospital, Zhejiang University, China, since April 2013.

We analyzed all consecutive patients aged $>18$ years undergoing first time isolated or concomitant AVR at the center from January $1^{\text {st }}, 2013$ to December $31^{\text {st }}$, 2015. Patients requiring a composite valve vascular prosthesis procedure were excluded.

In total, 869 patients were included in this study. Baseline, operative, and outcome data of the patients were prospectively collected, validated, and entered into the database, which was queried retrospectively. A 30-day postoperative follow-up was conducted for all discharged patients at the outpatient clinic.

\section{PPM and definitions}

Body surface area (BSA) was derived from the Dubois formula. The aortic valve prosthesis effective valve orifice area (EOA) was derived from in vitro measurements provided by the manufacturers and from scientific publications, as outlined in Table 1.

EOA was divided by BSA to obtain the effective orifice area index (EOAi). PPM was defined as EOAi $\leq$ $0.85 \mathrm{~cm}^{2} / \mathrm{m}^{2}$ [8]. EOAi $\leq 0.65 \mathrm{~cm}^{2} / \mathrm{m}^{2}$ was considered severe PPM.

Chronic renal insufficiency: serum creatinine $\geq 2 \mathrm{mg} /$ dl. Peripheral arterial disease: claudication, carotid stenosis $>50 \%$ or previous/planned intervention on the abdominal aorta, limb arteries or carotids. Coronary artery disease: $\geq 50 \%$ reduction in one or more coronary vessels in single or more plane angiographic images. Emergency surgery: operation required within $24 \mathrm{~h}$ of onset of symptoms. Postoperative renal failure: the increase in baseline creatinine greater than $2 \mathrm{mg} / \mathrm{dl}$.

\section{Surgical technique}

The surgical records of all patients were reviewed. A total of 210 aortic valve bioprostheses and 659 aortic valve mechanical prostheses were implanted. The prostheses used included: Hancock II Procine Bioprosthesis (120 patients) and Mosaic Procine Bioprosthetic Valves (four patients) (Medtronic, Inc, Minneapolis, Minn), Biocor Stented Tissue Valve (47 patients) (St Jude Medical, Inc, St Paul, Minn), Carpentier-Edwards Perimount (32 patients) and Carpentier-Edwards Perimount Magna Ease (seven patients) (Baxter Healthcare Corp, Edwards Division, Santa Ana, Calif), CarboMedics Orbis Universal Valve (517 patients) (CarboMedics, Inc, Austin, TX), ATS Open Pivot 500FA, 500DM (ten patients) and ATS Open Pivot AP360 (two patients) (ATS Medical, Inc, Minneapolis, Minn), St Jude Regent Valve (40 patients) and St Jude Master Series Heart Valves (90 patients) (St Jude Medical, Inc, St Paul, Minn) (Table 1).

Table 1 In vivo effective orifice area values $\left(\mathrm{cm}^{2}\right)$ corresponding to each valve

\begin{tabular}{|c|c|c|c|c|c|c|c|c|c|c|}
\hline Valve prosthesis & No. of patients n(\%) & $\begin{array}{l}17 \mathrm{~mm} \\
1.8 \%\end{array}$ & $\begin{array}{l}19 \mathrm{~mm} \\
8.7 \%\end{array}$ & $\begin{array}{l}21 \mathrm{~mm} \\
27.7 \%\end{array}$ & $\begin{array}{l}23 \mathrm{~mm} \\
30.0 \%\end{array}$ & $\begin{array}{l}25 \mathrm{~mm} \\
22.6 \%\end{array}$ & $\begin{array}{l}27 \mathrm{~mm} \\
7.0 \%\end{array}$ & $\begin{array}{l}29 \mathrm{~mm} \\
1.5 \%\end{array}$ & $\begin{array}{l}31 \mathrm{~mm} \\
0.6 \%\end{array}$ & ref \\
\hline \multicolumn{11}{|l|}{ Mechanical } \\
\hline CarboMedics Orbis Universal Valve & $517(59.5)$ & 1 & 1.2 & 1.5 & 1.7 & 2 & 2.5 & 2.6 & 2.7 & [19] \\
\hline ATS Open Pivot 500FA (size, mm) & $10(1.2)$ & $0.6(16)$ & 1 & 1.6 & 1.8 & 2.2 & 2.5 & 3.1 & & [15] \\
\hline ATS Open Pivot AP360 (size, mm) & $2(0.2)$ & $1.2(16)$ & $1.5(18)$ & $1.7(20)$ & $2.1(22)$ & $2.5(24)$ & $3.1(26)$ & & & [20] \\
\hline St. Jude Regent Valve & $40(4.6)$ & 1.2 & 1.6 & 2 & 2.2 & 2.5 & 3.6 & 4.4 & & [21] \\
\hline St. Jude Master Series & $90(10.4)$ & 1 & 1.2 & 1.5 & 2.0 & 2.6 & 3.1 & & & [22] \\
\hline \multicolumn{11}{|l|}{ Bioprosthesis } \\
\hline Hancock II Procine Bioprosthesis & $120(13.8)$ & & & 1.2 & 1.3 & 1.5 & 1.6 & 1.6 & & [19] \\
\hline Mosaic Procine Bioprosthetic Valve & $4(0.5)$ & & 1.1 & 1.2 & 1.4 & 1.7 & 1.8 & 2 & & [23] \\
\hline St. Jude Biocor Stented Tissue Valve & $47(5.4)$ & & & 1.3 & 1.6 & 1.8 & 2 & & & [24] \\
\hline Carpentier-Ed PERIMOUNT & $32(3.7)$ & & 1.1 & 1.3 & 1.5 & 1.8 & 2.1 & 2.2 & & [19] \\
\hline Carpentier-Ed PERIMOUNT MAGNA & $7(0.8)$ & & 1.3 & 1.7 & 2.1 & 2.3 & & & & [24] \\
\hline PPM rate of each valve sizes & & $81.2 \%$ & $52.6 \%$ & $19.1 \%$ & $10.7 \%$ & $4.6 \%$ & $3.3 \%$ & $0 \%$ & $0 \%$ & \\
\hline
\end{tabular}

PPM prosthesis patient mismatch, ref reference 
An isolated or concomitant aortic valve replacement was performed in all patients. Concomitant operations in some of the patients included coronary artery bypass grafting and other heart valve procedures. Standard anesthesia and surgical technique, extracorporeal circulation and myocardial protection methods were used. Most of the patients were approached through a full median sternotomy followed by antegrade 4:1 cold blood cardioplegia for myocardial protection. Antegrade plus retrograde cardioplegia was applied for patientis with coronary stenosis. Intermittent perfusion of cold blood cardioplegia was maintained, with a frequency of once every $20 \mathrm{~min}$.

After consulting the patients and their relatives preoperatively, a decision on the type of prosthesis was made by the surgeon, taking into consideration the preoperative characteristics and the intraoperative findings. The largest suitable prosthesis was chosen. When performing the valve replacement procedure, we applied simple interrupted mattress suturing with pledget on the left ventricular side of the annulus to ensure a larger orifice area and a shorter cross-clamp time.

\section{Statistical analysis}

The Kolmogorov-Smirnov test and/or Shapiro-Wilk test was used to verify the normality of the quantitative variables as appropriate. Continuous variables were presented as mean \pm standard deviation, whether Gaussian distributed or median (interquartile range). Categorical variables were expressed as an absolute number (percentage). Pearson's $\chi^{2}$ test was used for descriptive, univariate statistics, such as the comparison of portions, while Student's unpaired T-test was used for normally distributed data comparisons. The Mann-Whitney $U$ test was used for group comparison of continuous non-Gaussian distributed variables. Two-tailed $P$-values were derived from the calculated test statistics, and $P \leq 0.05$ was considered statistically significant. Binary multivariate logistic regression analysis by the forward method was performed to study the factors affecting PPM and mortality. SPSS software for windows (version 19.0) was used to analyze the data.

\section{Results}

\section{Patient characteristics and preoperative data}

A total of 869 consecutive patients were included in the study. PPM was detected in $15.9 \%(138 / 869)$ of the patients. Four patients $(0.5 \%)$ met the criteria for severe PPM. Smaller valve sizes are related to higher rate of PPM (Table 1). Compared with the non-PPM group, patients with PPM were older and had a higher prevalence of diabetes, coronary heart disease, AS, and preoperative left ventricular ejection fraction (LVEF). But the incidence of smoking history and aortic regurgitation was relatively low in PPM patients (Table 2).

\section{Operative data}

As shown in Table 3, there were no significant differences between the groups regarding cardiopulmonary bypass (CPB) time, aortic cross-clamp time, and mitral valve procedure combined. However, remarkably more patients with prosthesis-patient mismatch were implanted with a bioprosthetic aortic valve.

\section{Factors affecting prosthesis-patient mismatch}

According to a multivariate logistic regression analysis including all preoperative and intraoperative variables, patients with PPM had a higher incidence of female gender $(P<0.001$; OR $=0.307 ; 95 \%$ CI, 0.19-0.486), a higher incidence of AS $(P=0.014$; OR $=1.725 ; 95 \% \mathrm{CI}, 1.118-2.663)$, higher body mass index (BMI) $(P<0.001 ; \mathrm{OR}=1.092 ; 95 \%$ CI, 1.029-1.160), and more frequently received a bioprosthesis $(P<0.001$; OR $=13.907$; 95\% CI, 8.703-22.222) than those without a mismatch (Table 4).

\section{Major postoperative complications}

There were no significant differences between the two groups regarding most of the postoperative patient data and complications, including perioperative blood transfusion, ventilation time, reintubation, duration of first time in ICU, reentering ICU, chest tube output, reoperation, sternal wound infection, postop stroke, postop renal failure, persistent atrial fibrillation (AF), multi organ failure, and length of hospital stay $(p>0.05)$. However, all-cause postoperative 30-day mortality was higher in the PPM group than in the non-PPM group $(2.1 \%$ vs $0.5 \%, p=0.050)$.

\section{Factors affecting postoperative mortality}

Seven patients $(0.8 \%)$ died during the postoperative hospitalization period, three $(2.1 \%)$ with and four $(0.5 \%)$ without PPM $(p=0.050)$. Five deaths were cardiac related; the other two patients (both without PPM) died due to severe infection. No patient died intraoperatively or within 30 days post discharge.

A binary multivariate logistic regression model was constructed to analyze factors relating to all-cause death (Table 5). The results of the analysis showed that patients with a smoking history $(P=0.001$; OR $=44.780 ; 95 \% \mathrm{CI}$, 4.303-466.014) and a lower preoperative left ventricular ejection fraction (LVEF) $(P=0.004 ; \mathrm{OR}=0.884 ; 95 \% \mathrm{CI}$, 0.813-0.961) had a higher incidence of postoperative death. More strikingly, prosthesis-patient mismatch was found to be associated with global or cardiac early mortality $(P=0.005$; OR $=16.493 ; 95 \% \mathrm{CI}, 2.306-117.950)$.

\section{Discussion}

Based on the aforementioned definitions, the incidence of PPM in our single-centered cohort was $15.9 \%$, and only $0.5 \%$ of the cases met the criteria for severe PPM. Although highly variable, PPM rates in 
Table 2 Preoperative patient characteristics

\begin{tabular}{|c|c|c|c|}
\hline Preoperative data & Non-PPM $(n=731)$ & $\operatorname{PPM}(n=138)$ & $P$ value \\
\hline Age, y & $56(47-62)$ & $64(55-69)$ & $<0.001$ \\
\hline Male & $394(54 \%)$ & $57(41 \%)$ & 0.07 \\
\hline BMI(kg/m2) & $22.58 \pm 3.29$ & $23.51 \pm 5.92$ & 0.076 \\
\hline $\mathrm{BSA}(\mathrm{m} 2)$ & $1.61 \pm 0.17$ & $1.60 \pm 0.14$ & 0.484 \\
\hline Smoking history & 138(18.9\%) & $14(10.1 \%)$ & 0.014 \\
\hline Diabetes & $63(8.6 \%)$ & $22(15.9 \%)$ & 0.008 \\
\hline Hypertension & $178(24.4 \%)$ & $39(28.1 \%)$ & 0.336 \\
\hline Chronic renal insufficiency & $23(3.1 \%)$ & $5(3.6 \%)$ & 0.77 \\
\hline Peripheral arterial disease & $21(2.9 \%)$ & $5(3.6 \%)$ & 0.64 \\
\hline Cerebrovascular accident: & $15(2.1 \%)$ & $2(1.1 \%)$ & 0.99 \\
\hline Coronary heart disease & $78(10.7 \%)$ & $24(17.4 \%)$ & 0.024 \\
\hline NYHA functional class ( $\geq$ III) & $260(35.6 \%)$ & $51(37.1 \%)$ & 0.772 \\
\hline AF & $212(29.0 \%)$ & $42(30.1 \%)$ & 0.76 \\
\hline Previous myocardial infarction & $1(0.1 \%)$ & $1(1.1 \%)$ & 0.293 \\
\hline AS & 399(55.0\%) & $90(65.1 \%)$ & 0.031 \\
\hline Aortic regurgitation (moderate to severe) & $508(69.5 \%)$ & $79(57.1 \%)$ & 0.006 \\
\hline LVEF & $61.02 \pm 8.99$ & $62.00 \pm 9.18$ & 0.105 \\
\hline Emergency surgery & $3(0.4 \%)$ & $0(0.0 \%)$ & 0.99 \\
\hline Aspirin within 5 days before surgery & $5(0.7 \%)$ & $1(1.1 \%)$ & 0.99 \\
\hline Clopidogrel within 5 days before surgery & $1(0.1 \%)$ & $1(1.1 \%)$ & 0.293 \\
\hline
\end{tabular}

PPM prosthesis-patient mismatch; BMI body mass index; BSA body surface area; NYHA New York Heart Association; AF atrial fibrillation; $A S$ aortic valve stenosis; LVEF left ventricular ejection fraction

most of the literature were higher than $20 \%$ [8]. The low rate of PPM in this study might be related to the particular physical condition of East Asians. First, East Asian population has considerably smaller body surface area than western populations. Also, the patients in this district are generally younger due to higher incidence of rheumatic causes, demanding more mechanical prosthesis, which may explain the lower incidence of PPM. A similar low rate of PPM has been reported by Japanese and Indian scientists $[9,10]$.

Table 3 Characteristics of the surgical procedure

\begin{tabular}{lllc}
\hline Intraoperative data & $\begin{array}{l}\text { Non PPM } \\
(n=731)\end{array}$ & PPM(138) & $P$ value \\
\hline CPB time & $83(69-94)$ & $83(69-93)$ & 0.98 \\
Cross-clamp time & $51(42-64)$ & $50(42-60)$ & 0.33 \\
Bioprosthesis & $124(17.0 \%)$ & $87(63.1 \%)$ & $<0.001$ \\
Concomitant procedure & & & \\
$\quad$ Mitral valve procedure & $397(54.3 \%)$ & $77(56.1 \%)$ & 0.78 \\
Tricuspid valve procedure & $96(13.1 \%)$ & $17(12.3 \%)$ & 0.79 \\
$\quad$ CABG & $14(1.9 \%)$ & $8(6.1 \%)$ & 0.015 \\
\hline $\begin{array}{l}\text { PPM prosthesis-patient mismatch; CPB cardiopulmonary bypass; CABG coronary } \\
\text { artery bypass grafting }\end{array}$ & & &
\end{tabular}

\section{Predictors of PPM}

We performed logistic regression analysis and found AS to be an independent risk factor for PPM. The reason why PPM occurs more frequently in patients with AS than aortic regurgitation is that patients with a stenotic native aortic valve tend to have smaller valvular annuli. It is also one of the reasons why older people, observed more frequently with calcified AS, had a higher incidence of mismatch. Another reason is that older patients, especially those aged over 65, were implanted with a bioprosthetic valve. Mechanical valves, compared to stented bioprostheses, have a more favorable relationship between the external diameter and the EOA [11], thus reducing the incidence of PPM. Diabetes and atherosclerosis may also be related to AS and old age, indirectly influencing the rate of PPM.

Table 4 Logistic regression model for prosthesis-patient mismatch

\begin{tabular}{lllll}
\hline Variables & Mean or $\%$ & OR & $95 \% \mathrm{Cl}$ & $P$-Values \\
\hline Female & $48.1 \%$ & 0.307 & $0.194-0.486$ & $<0.001$ \\
AS & $56.6 \%$ & 1.725 & $1.118-2.663$ & 0.014 \\
Bioprosthesis & $24.3 \%$ & 13.907 & $8.703-22.222$ & $<0.001$ \\
BMI & 29.6 & 1.092 & $1.029-1.160$ & $<0.001$ \\
\hline OR odd ratio; $\mathrm{Cl}$ confidence interval; AS aortic stenosis; BMl body mass index
\end{tabular}

OR odd ratio; $\mathrm{Cl}$ confidence interval; $A S$ aortic stenosis; $B M I$ body mass index 
Table 5 Logistic regression model for postoperative 30-day global mortality

\begin{tabular}{llllc}
\hline Variables & Mean or \% & \multicolumn{1}{l}{ OR } & $95 \% \mathrm{Cl}$ & $P$-values \\
\hline Smoking history & $17.5 \%$ & 44.780 & $4.303-466.014$ & 0.001 \\
PPM & $15.9 \%$ & 16.493 & $2.306-117.950$ & 0.005 \\
Preoperative LVEF & 61.33 & 0.884 & $0.813-0.961$ & 0.004
\end{tabular}

$O R$ odd ratio; $C l$ confidence interval; $P P M$ prosthesis-patient mismatch; $L V E F$ left ventricular ejection fraction

We also found that there were more female patients in the PPM group (59\% female and 41\% male), consistent with other studies [12]. The study showed that women had smaller aortic root diameters than men [13], making them more likely to be implanted with a small sized valve prosthesis. This may explain why there were more smokers in the non-PPM group of our study. Our study also showed that PPM was associated with higher BMI. Therefore, weight control should be urged in obese patients to minimize the adverse effects of PPM.

\section{Effect of PPM on early mortality}

There were no obvious differences regarding early postoperative patient data and complications between the two groups. However, logistic regression analysis showed that PPM was an independent factor predicting postoperative 30-day all-cause mortality, along with smoking history and low preoperative LVEF. The high mortality may be associated with the increased hemodynamic burden imposed by PPM. Further, the combination of poor ventricular function and moderate to severe PPM may dramatically increase mortality risk [14].

\section{Clinical implication and prevention}

Some studies have shown that PPM affects long- and short-term postoperative morbidity and mortality [14, 15], whereas other studies have proven that even severe PPM does not increase the incidence of adverse outcomes $[4,16]$.

Aortic root enlargement surgery is an alternative procedure to avoid PPM. However, preventative root enlargement surgery may be related to prolonged off-pump time and increased risk $[17,18]$. Therefore, considering the relatively low rate of PPM in China, we did not take aggressive root enlargement as a routine procedure in patients with a risk of mismatch. However, the implantation of newer-generation biological or mechanical prostheses with or without aortic annular enlargement should be considered according to the characteristics of the patient and the risk-benefit ratio for carrying out a particular procedure in an individual patient.

Out data have shown that although PPM does not affect the incidence of postoperative complications, allcause early mortality of the patients did increase. Therefore, a randomized controlled trial will be carried out next to evaluate the effect of root enlargement strategies in selected young patients.

The results of this retrospective study have updated our understanding of PPM and encourage a positive view of preventative root enlargement strategies in patients with PPM.

\section{Limitations of the study}

This was a retrospective study; the analysis, therefore, has inherent disadvantages. The recorded differences in patient outcomes could originate from smaller recorded or unrecorded differences between the two groups.

EOA was predicted by reference tables, which may not reflect the actual in vivo values of the EOAi. The effect of PPM on long-term outcomes and survival was not studied. Moreover, this was a single-centered analysis, thus the extrapolation of the results should be treated cautiously. However the sample size is acceptable. Comparing to a multi-centered study, our single-center analysis have the advantage of minimizing the deviation in patient surgical outcomes caused by uneven surgical procedures, varied skills of surgeons and different myocardial protection strategies.

Nevertheless, a randomized prospective multi-centered clinical trial is needed for further evaluation of the effect of PPM on longer term hemodynamic function, left ventricular function, and overall patient outcomes.

\section{Conclusions}

This study demonstrates that female gender, aortic stenosis, bioprosthesis, and high BMI are risk factors for PPM in patients undergoing AVR. PPM is associated with a higher short-term mortality after AVR in China.

\section{Abbreviations}

AF: Atrial fibrillation; AS: Aortic stenosis; AVR: Aortic valve replacement; BMI: Body mass index; BSA: Body surface are; CABG: Coronary artery bypass grafting; Cl: Confidence interval; CPB: Cardiopulmonary bypass; EOA: Effective orifice area; EOAi: Effective orifice area index; ICU: Intensive care unit; LVEF: Left ventricular ejection fracture; NYHA: New York Heart Association; OR: Odd ratio; PPM: Prosthesis-patient mismatch

\section{Acknowledgements}

The authors would like to thank the anesthetists, intensivists, heart surgeons, nursing staff, perfusionists and the laboratory department at the First Affiliated Hospital, Zhejiang University for the collection and management of the data presented in this report. The authors also would like to thank Dr. Malik Akuffu Armah of Zhejiang University for language editing and proof reading of the manuscript

\section{Funding \\ Not applicable.}

\section{Availability of data and material}

The datasets during and/or analysed during the current study available from the corresponding author on reasonable request.

\section{Authors' contributions}

$J Z$ and LC analyzed and interpreted the patient data, and wrote the paper. $L M$ and $R L$ prepared the tables and figure, and were major contributors in writing the manuscript. $L G$ and $H Z$ drafted the final manuscript. LG revised 
the manuscript. LG and JZ contributed equally to this study. All authors read and approved the final manuscript.

\section{Competing interests}

The authors declare that they have no competing interests.

\section{Consent for publication}

Not applicable.

Ethics approval and consent to participate

Written informed consent waived by the Hospital Review Board.

\section{Publisher's Note}

Springer Nature remains neutral with regard to jurisdictional claims in published maps and institutional affiliations.

Received: 11 September 2016 Accepted: 10 May 2017

Published online: 25 May 2017

\section{References}

1. Rahimtoola SH. The problem of valve prosthesis-patient mismatch. Circulation. 1978;58(1):20-4

2. Howell NJ, Keogh BE, Ray D, et al. Patient-prosthesis mismatch in patients with aortic stenosis undergoing isolated aortic valve replacement does not affect survival. Ann Thorac Surg. 2010;89(1):60-4.

3. Howell NJ, Keogh BE, Barnet $\mathrm{V}$, et al. Patient-prosthesis mismatch does not affect survival following aortic valve replacement. Eur J Cardiothorac Surg. 2006;30(1):10-4

4. Sportelli E, Regesta T, Salsano A, et al. Does patient-prosthesis mismatch after aortic valve replacement affect survival and quality of life in elderly patients? J Cardiovasc Med. 2016;17(2):137-43.

5. Hong S, Yi GJ, Youn YN, Lee S, Yoo KJ, Chang BC. Effect of the prosthesispatient mismatch on long-term clinical outcomes after isolated aortic valve replacement for aortic stenosis: A prospective observational study. J Thorac Cardiov Sur. 2013;146(5):1098-104.

6. Fuster RG, Montero Argudo JA, Albarova OG, et al. Patient-prosthesis mismatch in aortic valve replacement: really tolerable? Eur J Cardiothorac Surg. 2005;27(3):441-9. discussion 9.

7. Zhou XM, Zhuang W, Hu JG, Li JM, Yu JF, Jiang L. Low-dose anticoagulation in Chinese patients with mechanical heart valves. Asian Cardiovasc Thorac Ann. 2005;13(4):341-4.

8. Pibarot P, Dumesnil JG. Prosthesis-patient mismatch: definition, clinical impact, and prevention. Heart. 2006;92(8):1022-9.

9. Kaminishi Y, Misawa Y, Kobayashi J, et al. Patient-prosthesis mismatch in patients with aortic valve replacement. Gen Thorac Cardiovasc Surg. 2013; 61(5):274-9.

10. Joshi SS, Ashwini T, George A, Jagadeesh AM. Patient prosthesis mismatch after aortic valve replacement: An Indian perspective. Ann Card Anaesth. 2016;19(1):84-8

11. Muneretto C, Bisleri G, Negri A, Manfredi J. The concept of patientprosthesis mismatch. J Heart Valve Dis. 2004;13 Suppl 1:S59-62.

12. Head SJ, Mokhles MM, Osnabrugge RL, et al. The impact of prosthesispatient mismatch on long-term survival after aortic valve replacement: a systematic review and meta-analysis of 34 observational studies comprising 27186 patients with 133141 patient-years. Eur Heart J. 2012;33(12):1518-29.

13. Bonderman D, Graf A, Kammerlander AA, et al. Factors determining patientprosthesis mismatch after aortic valve replacement-a prospective cohort study. PLoS One. 2013;8(12):e81940.

14. Blais C, Dumesnil JG, Baillot R, Simard S, Doyle D, Pibarot P. Impact of valve prosthesis-patient mismatch on short-term mortality after aortic valve replacement. Circulation. 2003;108(8):983-8.

15. Walther T, Rastan A, Falk V, et al. Patient prosthesis mismatch affects shortand long-term outcomes after aortic valve replacement. Eur J Cardiothorac Surg. 2006:30(1):15-9.

16. Hoffmann G, Ogbamicael SA, Jochens A, et al. Impact of patientprosthesis mismatch following aortic valve replacement on short-term survival: a retrospective single center analysis of 632 consecutive patients with isolated stented biological aortic valve replacement. Thorac Cardiov Surg. 2014;62(6):469-74.

17. Sommers KE, David TE. Aortic valve replacement with patch enlargement of the aortic annulus. Ann Thorac Surg. 1997;63(6):1608-12.
18. Carrier M, Pellerin M, Perrault LP, et al. Experience with the 19-mm Carpentier-Edwards pericardial bioprosthesis in the elderly. Ann Thorac Surg. 2001;71(5 Suppl):S249-52.

19. Pibarot $P$, Dumesnil JG. Hemodynamic and clinical impact of prosthesispatient mismatch in the aortic valve position and its prevention. J Am Coll Cardiol. 2000;36(4):1131-41.

20. Sakamoto $Y$, Hashimoto K. Update on aortic valve prosthesis-patient mismatch in Japan. Gen Thorac Cardiovasc Surg. 2013;61(12):669-75.

21. Bach DS, Sakwa MP, Goldbach M, Petracek MR, Emery RW, Mohr FW. Hemodynamics and early clinical performance of the St. Jude Medical Regent mechanical aortic valve. Ann Thorac Surg. 2002;74(6):2003-9. discussion 9.

22. Tech Specs of Masters Series Mechanical Heart Valve. http://professional.sjm. com/. Available at: http://professional.sjm.com/products/sh/mechanicalvalves/aortic-mitral/masters-series\#tech-specs. Accessed 20 Mar 2016.

23. Thomson DJ, Jamieson WR, Dumesnil JG, et al. Medtronic mosaic porcine bioprosthesis satisfactory early clinical performance. Ann Thorac Surg. 1998; 66(6 Suppl):S122-5.

24. Pibarot P, Dumesnil JG. Prosthetic heart valves: selection of the optimal prosthesis and long-term management. Circulation. 2009:119(7):1034-48.

\section{Submit your next manuscript to BioMed Central and we will help you at every step:}

- We accept pre-submission inquiries

- Our selector tool helps you to find the most relevant journal

- We provide round the clock customer support

- Convenient online submission

- Thorough peer review

- Inclusion in PubMed and all major indexing services

- Maximum visibility for your research

Submit your manuscript at www.biomedcentral.com/submit
Biomed Central 